\title{
Atividade microbiana e enzimática em solo após a aplicação de xisto retortado
}

\author{
Marta Eliane Doumer(1), Sandro José Giacomini(1), Carlos Augusto Posser Silveira ${ }^{(2)}$, \\ Douglas Adams Weiler(1), Leonardo Mendes Bastos $^{(1)}$ e Luana Liberalesso de Freitas ${ }^{(1)}$
}

(1)Universidade Federal de Santa Maria, Centro de Ciências Rurais, Departamento de Solos, Caixa Postal 221, CEP 97105-900 Santa Maria, RS. E-mail: martaelianedoumer@gmail.com, sjgiacomini@gmail.com, douglasweiler@yahoo.com.br, leonardombastos@gmail.com, luh_liberalesso@hotmail.com (2)Embrapa Clima Temperado, Rodovia BR 392, Km 78, Caixa Postal 403, CEP $96010-971$ Pelotas, RS. E-mail: augusto.posser@cpact.embrapa.br

Resumo - O objetivo deste trabalho foi avaliar o efeito da aplicação de doses crescentes de xisto retortado (XR) sobre características biológicas indicadoras da qualidade do solo. Foram realizados experimentos, em Argissolo Vermelho distrófico arênico, em condições de laboratório e de campo. Em laboratório, os tratamentos consistiram da aplicação ao solo de sete diferentes doses de XR (0, 300, 450, 600, 750, 1.500 e $\left.3.000 \mathrm{~kg} \mathrm{ha}^{-1}\right)$. Em campo, os tratamentos foram compostos por quatro diferentes doses de XR $\left(0,750,1.500,3.000 \mathrm{~kg} \mathrm{ha}^{-1}\right)$ combinadas à adubação mineral recomendada, avaliados em dois cultivos de feijão (Phaseolus vulgaris L.), no sistema plantio direto. Avaliaram-se: a evolução de $\mathrm{CO}_{2}$, o carbono da biomassa microbiana (CBM), a atividade enzimática do solo e o teste de ecotoxicidade. A aplicação de doses crescentes de XR melhorou a atividade microbiológica do solo, por reduzir a emissão de $\mathrm{CO}_{2}$ sem causar variação no $\mathrm{CBM}$ e sem provocar impactos negativos sobre a atividade enzimática do solo. Os resultados obtidos com as enzimas em condições de campo, após duas aplicações de XR, aliados aos de CBM, do quociente metabólico $\left(\mathrm{qCO}_{2}\right)$ e do teste ecotoxicológico, em condições de laboratório, indicam que o uso do XR não provoca a degradação biológica do solo.

Termos para indexação: biomassa microbiana, ecotoxicidade, enzimas do solo, mineralização do carbono, qualidade do solo.

\section{Microbial and enzymatic activities in the soil after application of retorted oil shale}

\begin{abstract}
The objective of this study was to assess the effect of increasing doses of retorted oil shale (ROS) application on the biological property indicators of soil quality. Experiments were carried out, under field and laboratory conditions, on a Hapludalf soil. In the laboratory, the treatments consisted of the application of seven different ROS rates $(0,300,450,600,750,1,500$ and 3,000 kg ha-1) to the soil. In the field, the treatments were composed by four different $\operatorname{ROS}$ rates $\left(0,750,1,500\right.$ and $\left.3,000 \mathrm{~kg} \mathrm{ha}^{-1}\right)$ combined with the recommended mineral fertilizer rate, evaluated in two croppings of common bean (Phaseolus vulgaris L.), under no-till system. $\mathrm{CO}_{2}$ evolution, microbial biomass carbon (MBC), soil enzyme activity and the ecotoxicity test were evaluated. Application of increasing ROS rates improved the soil microbial activity by decreasing $\mathrm{CO}_{2}$ emission and causing no variations in $\mathrm{MBC}$ nor negative impacts on the soil enzymatic activity. The results obtained with the enzymes under field conditions, after two ROS applications, allied to MBC results, and to the metabolic quocient $\left(\mathrm{qCO}_{2}\right)$ and to the ecotoxicity test, under laboratory conditions, show that the use of ROS cause no soil biological degradation.
\end{abstract}

Index terms: microbial biomass, ecotoxicity, soil enzymes, carbon mineralization, soil quality.

\section{Introdução}

O Brasil possui uma das maiores reservas mundiais de xisto, o qual apresenta em sua matriz mineral o querogênio, um complexo orgânico que se decompõe termicamente, produzindo óleo e gás. Na exploração do xisto, são gerados diversos subprodutos, dos quais se destaca o rejeito sólido proveniente da pirólise da rocha, o xisto retortado (XR). Este subproduto representa 80 a $90 \%$ do volume de xisto $(6.600 \mathrm{Mg})$ processado diariamente na Unidade de Industrialização do Xisto
(Pimentel et al., 2006), instalada em São Mateus do Sul (PR) sobre a Formação Irati, que contém a maior reserva brasileira de xisto. O grande volume de XR gerado e a necessidade de sua disposição no ambiente são os principais problemas que limitam o desenvolvimento da indústria do xisto (Stark \& Redente, 1990).

O XR apresenta estrutura lamelar, com argilominerais aluminossilicatos como principais constituintes e área superficial específica de $65 \mathrm{~m}^{2} \mathrm{~g}^{-1}$ (Miotto \& Machado, 2006; Pimentel et al., 2006), além de elevado teor de

Pesq. agropec. bras., Brasília, v.46, n.11, p.1538-1546, nov. 2011 
silício, entre outros elementos minerais essenciais às plantas (Pereira \& Vitti, 2004). Essas características podem viabilizar sua aplicação na síntese de materiais zeolíticos adsortivos (Miotto \& Machado, 2006) e, na agricultura, como fertilizante (Pereira \& Vitti, 2004). Com relação ao seu uso em solos agrícolas, o XR pode melhorar as condições físicas e aumentar a disponibilidade de nutrientes no solo. No entanto, o XR apresenta compostos como hidrocarbonetos (Afonso et al., 1991) e metais pesados (Stark \& Redente, 1990; Anjos \& Reissmann, 1996) e, conforme a dose aplicada, pode provocar a contaminação do solo. Contudo, resultados sobre os efeitos da aplicação de XR sobre indicadores da qualidade do solo não foram localizados na literatura.

Alterações na qualidade do solo, provocadas pela aplicação de subprodutos, são frequentemente avaliadas por meio das características biológicas do solo (García-Gil et al., 2000; Trannin et al., 2007; Lambais \& Carmo, 2008; Souza et al., 2009). Em geral, a quantidade de C na biomassa microbiana, o quociente metabólico $\left(\mathrm{qCO}_{2}\right)$ e a atividade enzimática do solo são indicadores sensíveis e precoces de distúrbios naturais e antropogênicos (Lambais \& Carmo, 2008; Lagomarsino et al., 2009). Atualmente, testes ecotoxicológicos estão sendo incluídos em protocolos de monitoramento da contaminação dos solos (Sisinno et al., 2006). Assim, estudos nessa área são importantes para auxiliar na recomendação do uso do XR na agricultura.

O objetivo deste trabalho foi avaliar o efeito da aplicação de doses crescentes de xisto retortado (XR) sobre as características biológicas indicadoras de qualidade do solo.

\section{Materiais e Métodos}

Em condições controladas de laboratório, de janeiro a novembro de 2010, foram realizados experimentos para avaliar a atividade e o carbono da biomassa microbiana (CBM), a atividade enzimática e a ecotoxicidade, após a aplicação do XR ao solo. Em todos os experimentos, o solo utilizado foi um Argissolo Vermelho distrófico arênico coletado da camada $0-10 \mathrm{~cm}$. Com exceção do experimento para avaliar a ecotoxicidade, em que o solo utilizado foi coletado em área sob campo nativo, nos demais experimentos, o solo foi oriundo de uma área que estava sendo manejada sob plantio direto.
O XR foi proveniente da Unidade de Industrialização do Xisto, em São Mateus do Sul, PR. A coleta do XR foi realizada em outubro de 2008, dois dias após a sua saída do processo de retortagem, e foram coletados aproximadamente $5 \mathrm{Mg}$ de XR. Após a coleta, o XR foi moído e armazenado em sacos de ráfia, com capacidade para $50 \mathrm{~kg}$, mantidos em local seco e ao abrigo do sol e da chuva. O XR utilizado nos experimentos apresentava granulometria $<0,3 \mathrm{~mm}$ e características químicas conforme resultados apresentados na Tabela 1 .

A atividade microbiana foi avaliada em dois experimentos, o primeiro com duração de 60 dias e o segundo com 90 dias. No experimento 1, os tratamentos avaliados foram: solo $+750 \mathrm{~kg} \mathrm{ha}^{-1} \mathrm{de}$ XR (XR750); solo + $1.500 \mathrm{~kg} \mathrm{ha}^{-1}$ de XR (XR1500); solo $+3.000 \mathrm{~kg} \mathrm{ha}^{-1}$ de XR (XR3000); e o controle com solo, sem o XR (XR0). No experimento 2, foram

Tabela 1. Caracterização química do lote de xisto retortado (XR), coletado na Superintendência da Industrialização do Xisto, em São Mateus do Sul, PR, utilizado nos experimentos, e concentração máxima permitida (CMP) para metais pesados em condicionadores de solo.

\begin{tabular}{lcc}
\hline Parâmetro & & \\
\hline Sólidos $(\%)$ & Xisto retortado & - \\
Nitrogênio total $\left(\mathrm{mg} \mathrm{kg}^{-1}\right)$ & 96,2 & - \\
$\mathrm{C}(\%)^{(3)}$ & 152 & - \\
Fósforo $\left(\mathrm{mg} \mathrm{kg}^{-1}\right)$ & 6,16 & - \\
Potássio $\left(\mathrm{mg} \mathrm{kg}^{-1}\right)$ & 1.547 & - \\
Cálcio $\left(\mathrm{mg} \mathrm{kg}^{-1}\right)$ & 2.746 & - \\
Enxofre $\left(\mathrm{mg} \mathrm{kg}^{-1}\right)$ & 11.325 & - \\
Magnésio $\left(\mathrm{mg} \mathrm{kg}^{-1}\right)$ & 840 & - \\
Boro $\left(\mathrm{mg} \mathrm{kg}^{-1}\right)$ & 2.146 & - \\
Zinco $\left(\mathrm{mg} \mathrm{kg}^{-1}\right)$ & 76 & - \\
Manganês $\left(\mathrm{mg} \mathrm{kg}^{-1}\right)$ & 112 & - \\
Molibdênio $\left(\mathrm{mg} \mathrm{kg}^{-1}\right)$ & 233 & - \\
Cobalto $\left(\mathrm{mg} \mathrm{kg}^{-1}\right)$ & 7,1 & - \\
Sódio $\left(\mathrm{mg} \mathrm{kg}^{-1}\right)$ & 14 & - \\
Cloreto $\left(\mathrm{mg} \mathrm{kg}^{-1}\right)$ & 1.675 & - \\
Níquel $\left(\mathrm{mg} \mathrm{kg}^{-1}\right)$ & 359 & 175 \\
Cobre $\left(\mathrm{mg} \mathrm{kg}^{-1}\right)$ & 18 & - \\
Ferro $\left(\mathrm{mg} \mathrm{kg}^{-1}\right)$ & 69 & - \\
Ś́lica $+\mathrm{insolúveis}(\%)_{\text {Arsênio }\left(\mathrm{mg} \mathrm{kg}^{-1}\right)}$ & 12.934 & - \\
Selênio $\left(\mathrm{mg} \mathrm{kg}^{-1}\right)$ & 71,8 & 20 \\
Mercúrio $\left(\mathrm{mg} \mathrm{kg}^{-1}\right)$ & 6,8 & 80 \\
Cromo $\left(\mathrm{mg} \mathrm{kg}^{-1}\right)$ & $<0,4$ & 2,5 \\
Chumbo $\left(\mathrm{mg} \mathrm{kg}^{-1}\right)$ & 0,19 & 500 \\
Cádmio $\left(\mathrm{mg} \mathrm{kg}^{-1}\right)$ & 7,7 & 300 \\
\hline
\end{tabular}

${ }^{(1)}$ Determinado pela Bioagri Ambiental. ${ }^{(2)}$ De acordo com a Portaria do MAPA número 402 (Brasil, 2010). ${ }^{(3)}$ Determinado no Laboratório de Microbiologia do Solo e Ambiente da Universidade Federal de Santa Maria. 
avaliados os mesmos tratamentos do experimento 1 , tendo sido incluídos outros três tratamentos: solo + $300 \mathrm{~kg} \mathrm{ha}^{-1}$ de XR (XR300); solo + $450 \mathrm{~kg} \mathrm{ha}^{-1} \mathrm{de}$ XR (XR450); e solo + $600 \mathrm{~kg} \mathrm{ha}^{-1}$ de XR (XR600). Nos dois experimentos, utilizou-se o delineamento experimental inteiramente casualizado, com três repetições. Cada unidade experimental foi montada separadamente. Em recipientes cilíndricos de acrílico, foram colocados $114,4 \mathrm{~g}$ de solo úmido ( $100 \mathrm{~g}$ de solo seco a $105^{\circ} \mathrm{C}$ ), cuja umidade foi elevada à capacidade de campo. A quantidade de XR adicionada ao solo foi proporcionalàdose equivalente porhectare, cnsiderando sua incorporação à camada de $0-10 \mathrm{~cm}$ de um solo com densidade de $1,5 \mathrm{~g} \mathrm{~cm}^{-3}$. Assim, a quantidade de $\mathrm{XR}$ adicionada ao tratamento XR3000 foi de $2 \mathrm{~g} \mathrm{~kg}^{-1}$ solo seco (12,3 mg de $\mathrm{C} \mathrm{kg}^{-1}$ de solo). A mistura do solo úmido com o XR foi realizada manualmente, com auxílio de espátula e, em seguida, foi compactada até a densidade de $1,2 \mathrm{~g} \mathrm{~cm}^{-3}$. Nos dois experimentos, as unidades experimentais foram acondicionadas individualmente em frascos de vidro com capacidade de $800 \mathrm{~mL}$. Três unidades foram utilizadas como prova em branco, nas quais se colocou somente $\mathrm{NaOH}$, para captar o $\mathrm{CO}_{2}$ presente na atmosfera interior do frasco.

A avaliação da emissão de $\mathrm{CO}_{2}$ durante a incubação foi realizada sempre nas mesmas unidades experimentais. Em cada frasco de vidro, foi colocado um recipiente com volume de $2,5 \mathrm{~mL}$ de água para manter as condições de umidade no interior do frasco, a fim de diminuir a perda de água do solo. Para evitar a deficiência de $\mathrm{O}_{2}$, os frascos de vidro foram periodicamente abertos, para promover a renovação da atmosfera interna. Os tratamentos permaneceram em incubadora, nas mesmas condições das unidades experimentais utilizadas na avaliação da emissão de $\mathrm{CO}_{2}$. O CO $\mathrm{CO}_{2}$ liberado em cada tratamento foi captado em $10 \mathrm{~mL}$ de solução de $\mathrm{NaOH} 1 \mathrm{~mol} \mathrm{~L}^{-1}$, cujo excesso foi titulado com solução de $\mathrm{HCl} 1 \mathrm{~mol} \mathrm{~L}^{-1}$ (Stotzky, 1965).

O CBM e a atividade enzimática no solo foram avaliados aos 15, 30 e 60 dias após a incubação dos tratamentos do experimento 1. Para isso, foram montadas 36 unidades experimentais (quatro tratamentos x três repetições x três datas de avaliação), as quais foram acondicionadas em potes de vidro em triplicata. $\mathrm{O}$ procedimento adotado na montagem das unidades experimentais foi o mesmo descrito anteriormente. Em cada data de avaliação, foram analisadas 12 unidades experimentais. Os tratamentos permaneceram em incubadora, em ausência de luz e com temperatura controlada à $28 \pm 2^{\circ} \mathrm{C}$.

O CBM foi avaliado pelo método da fumigação-extração conforme Vance at al. (1987), com aplicação do fator de correção $\mathrm{Kc}$ de 0,33 , expresso pela fração do $\mathrm{C}$ da CBM recuperado após o processo de fumigação-extração (Sparling \& West, 1988). Com base nos valores de $\mathrm{CBM}$ e da emissão de $\mathrm{CO}_{2}$ medida até os 15 e 30 dias, foi determinado o $\mathrm{qCO}_{2}$, cujo valor representa a razão entre o $\mathrm{C}-\mathrm{CO}_{2}$ e o $\mathrm{C}$ da biomassa, medido no período considerado (Anderson \& Domsch, 1993). A atividade enzimática do solo foi avaliada pela medida de cinco enzimas: a atividade da desidrogenase (DHA), determinada conforme Thalmann (1968); a atividade da hidrólise do diacetato de fluoresceína (FDA), conforme Alef (1995); a atividade da fosfatase ácida, da $\beta$-glicosidase, da urease e da arilsulfatase, conforme descrito em Tabatabai (1994).

No solo dos tratamentos XR0 e XR1500, foram realizadas análises de hidrocarbonetos aromáticos policíclicos (HAP), em amostras coletadas no momento da incubação e 60 dias depois desta. As amostras de solo foram enviadas à Bioagri Ambiental (Piracicaba, SP), para a análise dos seguintes HPA: benzo(a)pireno, benzo(b)fluoranteno, benzo(k)fluoranteno, criseno, acenaftileno, fluoreno, antraceno, benzo(g,h,i)perileno, fenantreno, dibenzo(a,h)antraceno, indeno $(1,2,3, \mathrm{~cd})$ pireno, pireno, acenafteno, fluoranteno, naftaleno e benzo(a)antraceno. As análises dos HPA, na Bioagri Ambiental, foram realizadas conforme as metodologias SVOC's POP PA 76/USEPA 8270, 3535 (United States Environmental Protection Agency, 1996).

A ecotoxicidade foi avaliada no ensaio de comportamento, conforme a International Organization for Standardization (2002). O organismo utilizado no teste foi a minhoca da espécie Eisenia foetida (Oligochaeta, Lumbricidae). Foram testadas as doses de $375,750,1.500$ e $3.000 \mathrm{~kg} \mathrm{ha}^{-1}$ de XR. Para isso, amostras de $400 \mathrm{~g}$ de solo, com e sem XR e à umidade a $60 \%$ da capacidade de campo, foram colocadas no mesmo recipiente, separadas por meio de uma divisória móvel, que formava duas seções. Após a colocação das amostras, a divisória foi removida e, no local desta, foram colocadas 10 minhocas na superfície do solo. Ao final de 48 horas, realizou-se a contagem das minhocas presentes em cada seção do recipiente. O princípio deste ensaio é a exposição simultânea das minhocas 
às amostras de solo com e sem XR. A amostra é considerada tóxica (com a função de habitat do solo limitada), se forem encontradas mais de $80 \%$ das minhocas na seção do recipiente que contém a amostra de solo sem o XR.

O experimento a campo foi desenvolvido no ano de 2010, na área experimental do Departamento de Solos, da Universidade Federal de Santa Maria (UFSM), Santa Maria, RS, a $29^{\circ} 45^{\prime} \mathrm{S}, 53^{\circ} 42^{\prime} \mathrm{W}$ e à altitude de $95 \mathrm{~m}$. O clima da região, segundo Köppen, é classificado como subtropical úmido, tipo Cfa2. O solo da área é um Argissolo Vermelho distrófico arênico (Santos et al., 2006), com os seguintes atributos químicos na camada de $0-10 \mathrm{~cm}$ : $\mathrm{pH}, 5,4$; matéria orgânica, $18 \mathrm{~g} \mathrm{~kg}^{-1}$; P, $31 \mathrm{mg} \mathrm{dm}^{-3}$; K, $105 \mathrm{mg} \mathrm{dm}^{-3}$; $\mathrm{Mg}, 1,2 \mathrm{cmol}_{\mathrm{c}} \mathrm{dm}^{-3}$; Ca, 3,3 $\mathrm{cmol}_{\mathrm{c}} \mathrm{dm}^{-3}$; e $\mathrm{H}+\mathrm{Al}$, $2,3 \mathrm{cmol}_{\mathrm{c}} \mathrm{dm}^{-3}$.

Utilizou-se o delineamento experimental de blocos ao acaso, com quatro repetições, em parcelas de $25 \mathrm{~m}^{2}$ $(5 \mathrm{~m} \times 5 \mathrm{~m})$. Os tratamentos avaliados na cultura do feijão (Phaseolus vulgaris, L.) foram: adubação mineral com NPK (NPK + XR0); NPK + $750 \mathrm{~kg} \mathrm{ha}^{-1}$ de XR (NPK + XR750); NPK + $1.500 \mathrm{~kg} \mathrm{ha}^{-1}$ de XR $(\mathrm{NPK}+\mathrm{XR} 1500)$; e NPK + $3.000 \mathrm{~kg} \mathrm{ha}^{-1} \mathrm{de} \mathrm{XR}(\mathrm{NPK}+$ XR3000). A adubação mineral foi realizada ao plantio, aplicada à linha de semeadura, e consistiu de $150 \mathrm{~kg} \mathrm{ha}^{-1}$ de NPK na formulação 00-25-20 e $45 \mathrm{~kg} \mathrm{ha}^{-1}$ de ureia em cobertura. O XR foi aplicado manualmente a lanço à superfície do solo, antes da semeadura do feijão na área total das parcelas experimentais. O XR utilizado pertence ao mesmo lote de onde foi retirado o XR para o estudo de laboratório.

Os tratamentos foram avaliados em dois cultivos de feijoeiro, realizados na mesma área experimental. A semeadura do feijão, no primeiro e no segundo cultivos, foi realizada em 23/1/2010 e em 27/9/2010, respectivamente. A variedade de feijão utilizada nos dois cultivos foi a Iapar Tiziu, e o espaçamento entre linhas foi de $0,45 \mathrm{~m}$ com população final de 14 plantas por metro linear. Antes da semeadura, o Rhizobium tropici foi inoculado nas sementes de feijão. Nos dois cultivos, o feijão foi semeado com semeadora equipada para plantio direto sobre resíduos culturais de aveia-preta (Avena sativa L.).

Aavaliação do CBMe da atividade enzimática do solo foi realizada em amostras de solo da camada de $0-5 \mathrm{~cm}$, coletadas na entrelinha, após uma semana da aplicação dos tratamentos (A1) e no estádio de florescimento do feijão (A2), em ambos os cultivos. De cada parcela, foram retiradas cinco subamostras de solo, com auxílio de trado calador, que foram acondicionadas em sacos de plástico e passaram a constituir uma amostra única. No laboratório, as amostras foram homogeneizadas manualmente, peneiradas com malha de $2 \mathrm{~mm}$ e, em seguida, refrigeradas a $4^{\circ} \mathrm{C}$ até o momento das análises. As metodologias utilizadas para avaliar o CBM e a atividade enzimática foram as mesmas empregadas no estudo de laboratório.

Os dados foram submetidos à análise de variância e, quando ocorreram diferenças significativas pelo teste F, aplicaram-se o teste de Tukey a $5 \%$ de probabilidade e as análises de regressão com o programa estatístico Winstat (Machado \& Conceição, 2003).

\section{Resultados e Discussão}

A aplicação do xisto retortado (XR) ao solo, em condições de laboratório, afetou a emissão de $\mathrm{CO}_{2}$ (Figura 1), e os tratamentos que receberam doses crescentes de XR apresentaram menor respiração microbiana do que o tratamento controle (XR0). Ao final do experimento 1 e do experimento 2, os tratamentos com doses de XR a partir de $1.500 \mathrm{~kg} \mathrm{ha}^{-1} \mathrm{e}$ $750 \mathrm{~kg} \mathrm{ha}^{-1}$, respectivamente, apresentaram quantidades acumuladas de $\mathrm{CO}_{2}$ significativamente inferiores às do tratamento XR0. No tratamento XR3000, a redução média na quantidade de $\mathrm{CO}_{2}$ acumulada ao final dos dois experimentos, em comparação ao tratamento XR0, foi de 19\% (104 mg de C- $\mathrm{CO}_{2} \mathrm{~kg}^{-1}$ de solo). Essa diferença na quantidade de $\mathrm{CO}_{2}$, entre o tratamento XR3000 e o XR0, equivale a aproximadamente nove vezes a quantidade de $\mathrm{C}$ adicionada com o XR (12,3 $\left.\mathrm{mg} \mathrm{kg}^{-1}\right)$. Tais resultados indicam que, além do $\mathrm{C}$ adicionado com o XR ser de difícil biodegradação, o XR afetou a atividade microbiana, provocando diminuição na emissão de $\mathrm{CO}_{2}$.

A análise química do XR indicou que os valores de metais pesados foram baixos (Tabela 1) e inferiores aos permitidos em condicionadores de solo, conforme limites estabelecidos pelo Ministério da Agricultura, Abastecimento e Pecuária - MAPA (Brasil, 2010), e em lodos de esgoto segundo a resolução do Conselho Nacional do Meio Ambiente - Conama (Brasil, 2006). Em relação à presença de $\mathrm{HAP}$, a análise realizada no solo dos tratamentos XR0 e XR1500, no início e no final do experimento 1 , indicou que os teores de HAP 
foram menores que $0,01 \mathrm{mg} \mathrm{kg}^{-1}$, nas duas datas de avaliação, e podem ser aplicados até a dose equivalente a $1.500 \mathrm{~kg} \mathrm{ha}^{-1}$, segundo os valores orientadores de referência normatizados pela Companhia de Tecnologia de Saneamento Ambiental - Cetesb (São Paulo, 2005). Os valores de referência foram determinados a partir da análise de HAP, em 13 solos de áreas sob vegetação nativa, e os solos com valores menores ou iguais aos de referência são considerados solos "limpos". Com base nos resultados das análises de metais pesados e HAP do presente trabalho e de acordo com os valores

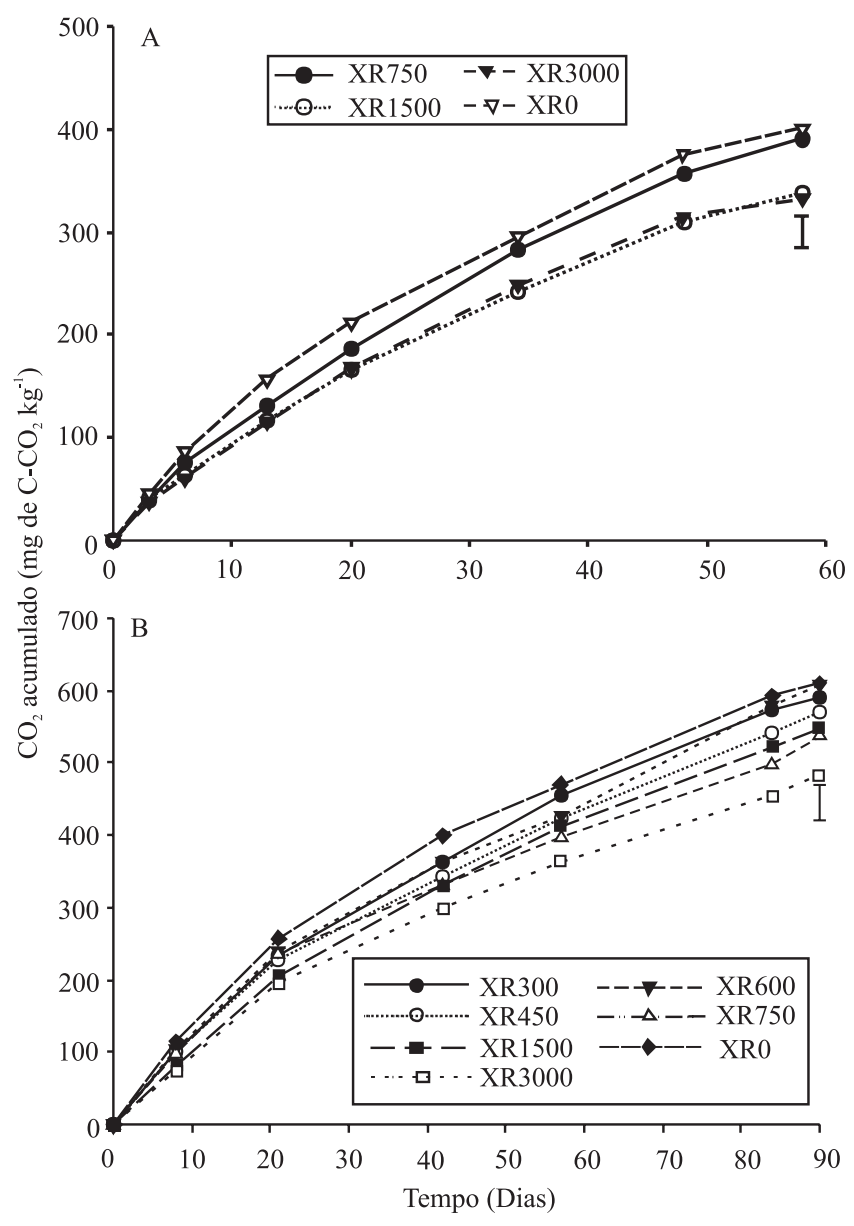

Figura 1. Quantidades acumuladas de $\mathrm{CO}_{2}$ do solo, incubado com doses crescentes de xisto retortado (XR), nos experimentos 1 (A) e 2 (B), da avaliação da atividade microbiana em condições de laboratório. XR0, controle; XR300, solo + $300 \mathrm{~kg} \mathrm{ha}^{-1}$ de XR; XR450, solo + $450 \mathrm{~kg} \mathrm{ha}^{-1}$ de XR; XR600, solo + $600 \mathrm{~kg} \mathrm{ha}^{-1}$ de XR; XR750, solo $+750 \mathrm{~kg} \mathrm{ha}^{-1} \mathrm{de}$ XR; XR1500, solo + $1.500 \mathrm{~kg} \mathrm{ha}^{-1}$ de XR; XR3000, solo + $3.000 \mathrm{~kg} \mathrm{ha}^{-1} \mathrm{de} X \mathrm{X}$. As barras verticais representam a diferença mínima significativa entre as médias de cada tratamento, pelo teste de Tukey, a 5\% de probabilidade. orientadores disponíveis (São Paulo, 2005; Brasil, 2006, 2010), pode-se concluir que esses fatores não foram a principal causa da redução na emissão de $\mathrm{CO}_{2}$ do solo dos tratamentos com XR.

$\mathrm{O}$ CBM dos tratamentos com XR não foi inferior ao do tratamento XR0 (Tabela 2). Ainda, pelo modelo quadrático ajustado aos dados de CBM aos 30 e 60 dias, foi possível determinar que os maiores valores de CBM podem ser obtidos com doses de $1.800 \mathrm{~kg} \mathrm{ha}^{-1}$ de XR.

Em relação ao $\mathrm{qCO}_{2}$, o qual reflete a eficiência microbiana (Brookes, 1995), verifica-se que os tratamentos com XR apresentaram valores semelhantes ou inferiores àqueles do tratamento controle, o que indica que a adição do XR não provocou estresse ou perturbação à biomassa microbiana do solo. Segundo Brookes (1995), menores valores de $\mathrm{qCO}_{2}$ representam aumento na eficiência microbiana, pois menor quantidade de $\mathrm{CO}_{2}$ é liberada por unidade de CBM.

Resultados sobre a emissão de $\mathrm{CO}_{2}$ e CBM, após a adição de XRao solo, não foram encontrados naliteratura consultada. Os resultados do presente trabalho, em que o $\mathrm{CBM}$ e o $\mathrm{qCO}_{2}$ foram afetados positivamente pelo uso do XR, indicam que a redução na emissão de $\mathrm{CO}_{2}$, com a aplicação do XR ao solo, não esteve relacionada a um efeito deletério do XR sobre a biomassa microbiana do solo (Figura 1). Portanto, a redução observada na emissão de $\mathrm{CO}_{2}$ pode ser atribuída a dois aspectos principais. O primeiro se refere a um possível aumento na eficiência de assimilação do $\mathrm{C}$ pela biomassa microbiana do solo, induzido pela presença do XR. $\mathrm{O}$ fato de o rendimento de assimilação do $\mathrm{C}$ representar a proporção do $\mathrm{C}$ atacado pelos microrganismos, que

Tabela 2. Carbono da biomassa microbiana (CBM ) e quociente metabólico $\left(\mathrm{qCO}_{2}\right)$, em solo incubado com doses crescentes de xisto retortado $(\mathrm{XR})^{(1)}$.

\begin{tabular}{lccccc}
\hline Tratamento $^{(2)}$ & \multicolumn{3}{c}{$\mathrm{CBM}\left(\mathrm{mg} \mathrm{kg}^{-1}\right)$} & \multicolumn{2}{c}{$\mathrm{qCO}_{2}\left(\mathrm{mg} \mathrm{CO}_{2} \mathrm{mg}^{-1} \mathrm{dia}^{-1} \mathrm{CBM}\right)$} \\
\cline { 2 - 6 } & \multicolumn{1}{c}{$15 \operatorname{dias}^{2} 0 \operatorname{dias}^{(3)}$} & $60 \operatorname{dias}^{(4)}$ & 15 dias & $30 \operatorname{dias}^{(5)}$ \\
\hline XR0 & $165 \mathrm{a}$ & $120 \mathrm{~b}$ & $224 \mathrm{~b}$ & $0,09 \mathrm{a}$ & $0,07 \mathrm{a}$ \\
XR750 & $140 \mathrm{a}$ & $195 \mathrm{a}$ & $408 \mathrm{a}$ & $0,08 \mathrm{a}$ & $0,04 \mathrm{~b}$ \\
XR1500 & $134 \mathrm{a}$ & $189 \mathrm{a}$ & $401 \mathrm{a}$ & $0,08 \mathrm{a}$ & $0,04 \mathrm{~b}$ \\
XR3000 & $199 \mathrm{a}$ & $176 \mathrm{a}$ & $323 \mathrm{ab}$ & $0,05 \mathrm{a}$ & $0,04 \mathrm{~b}$ \\
\hline CV (\%) & 23 & 13 & 17 & 17 & 20 \\
\hline
\end{tabular}

(1)Médias seguidas de letras iguais, nas colunas, não diferem entre si, pelo teste Tukey, a 5\% de probabilidade. ${ }^{(2)} \mathrm{XR} 0$, controle; XR750, solo + $750 \mathrm{~kg} \mathrm{ha}^{-1}$ de XR; XR1500, solo + $1.500 \mathrm{~kg} \mathrm{ha}^{-1}$ de XR; XR3000, solo $+3.000 \mathrm{~kg} \mathrm{ha}^{-1}$ de XR. ${ }^{(3)} \mathrm{y}=126,6+0,08 \mathrm{x}-0,00002 \mathrm{x}^{2}, \mathrm{R}^{2}=0,85^{*}$. ${ }^{(4)}$ $\mathrm{y}=237,9+0,22 \mathrm{x}-0,00007 \mathrm{x}^{2}, \mathrm{R}^{2}=0,89^{* *} \cdot{ }^{(5)} \mathrm{y}=0,09+0,00046 \mathrm{x}$

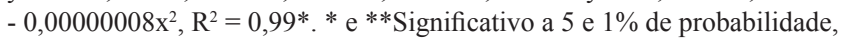
pelo teste $\mathrm{F}$, respectivamente. 
é transformado em biomassa microbiana (Sylvia et al., 1998), indica que o aumento nesse atributo resulta em maior proporção de biomassa formada por unidade de $\mathrm{C}$ atacado e em menor quantidade de $\mathrm{C}$ mineralizado até $\mathrm{CO}_{2}$. $\mathrm{O}$ segundo aspecto pode estar relacionado à mudança na taxa de decomposição da MOS, em razão da adição de um novo substrato ao solo (Kuzyakov et al., 2000). Esse efeito, denominado de "priming", pode ser positivo ou negativo e resultar, portanto, em aumento ou retardamento na taxa de mineralização da MOS (Kuzyakov, 2010). Os resultados do presente trabalho indicam que o XR provocou "priming" negativo, já que a sua aplicação ao solo provocou diminuição da evolução de $\mathrm{CO}_{2}$, em comparação ao tratamento controle. Zimmerman et al. (2011) apontam que a adição ao solo de substratos formados por um componente sortivo, como é o caso do XR, pode promover priming negativo e proporcionar maior proteção da MOS à mineralização.

Ao realizar a caracterização física e química do XR, Pimentel et al. (2006) verificaram que o XR apresenta, em sua composição, argilominerais de camada dupla (2:1) como ilita e montmorilonita. Nesse mesmo trabalho, o XR apresentou área superficial específica de $65 \mathrm{~m}^{2} \mathrm{~g}^{-1}$, valor semelhante ao obtido por Cessa et al. (2009) para argilas extraídas de um Latossolo Vermelho distroférrico, com textura muito argilosa. Essa elevada área superficial específica do XR, também pode ser consequência da presença de minerais silicatados e óxidos de ferro e de alumínio em sua composição (Cogo, 2008). Entre as características químicas apresentadas pelo XR estão os grupos funcionais silanoides, hidroxílicos e carboxílicos (Pimentel et al., 2006). Aliada à fração mineral do XR está a fração orgânica (C residual), composta por materiais orgânicos refratários, especialmente estruturas aromáticas, que são resistentes à decomposição microbiana. Embora quantitativamente o C aportado ao sistema pelo XR possa não ser significativo, é provável que os compostos orgânicos presentes em sua estrutura exerçam papel importante nas interações organominerais.

Considerando-se todas essas características do XR, pode-se dizer que o XR, quando adicionado ao solo, tem potencial para promover a proteção física e química da MOS e a adsorção de $\mathrm{C}$ lábil, além de promover um efeito "priming" negativo. As propriedades coloidais do XR devem aumentar a área superficial da matriz do solo, favorecer as associações com compostos orgânicos e minerais do solo, promovendo a agregação e, portanto, protegendo estruturas orgânicas mais lábeis. Este efeito estabilizante da complexação de superfície pode influenciar atributos físicos do solo, especialmente a distribuição do tamanho dos poros e tamanho de agregados e, com isso, afetar o acesso dos microrganismos e das enzimas extracelulares à MO fisicamente protegida no interior dos agregados. Correlação positiva entre a percentagem de argila e o conteúdo de $\mathrm{C}$ de um solo, com predominância de argilas 2:1 expansivas (esmectitas) e não expansivas (ilitas), foi observada por Wiseman \& Püttmann (2006).

Embora os resultados obtidos no presente trabalho não permitam confirmar que o XR tenha promovido a proteção da MOS contra o ataque microbiano, esta parece ser a principal causa da redução na emissão de $\mathrm{CO}_{2}$ verificada nos tratamentos com XR. Estudos futuros são necessários, para confirmar essa possível estabilização da MOS pelo XR. Especial atenção deve ser dada aos mecanismos pelos quais a textura do solo e o XR interagem e afetam a ciclagem do $\mathrm{C}$ e nutrientes presentes na MOS. Esses aspectos são importantes tanto do ponto de vista da estabilização da MOS, quanto do sequestro de $\mathrm{C}$ no solo e da disponibilidade de nutrientes às plantas e aos microrganismos do solo.

No teste ecotoxicológico, as amostras de solo que receberam doses equivalentes de 375, 750, $1.500 \mathrm{e}$ $3.000 \mathrm{~kg} \mathrm{ha}^{-1}$ de XR apresentaram, respectivamente, $58,65,53$ e $40 \%$ das dez minhocas utilizadas no teste. Nas amostras de solo sem XR usadas como controle para cada dose de XR, os percentuais foram de 42 , 35,47 e 60. Segundo a International Organization for Standardization (2002), a amostra é considerada tóxica, quando mais de $80 \%$ dos organismos usados no teste são encontrados na amostra usada como controle. Assim, os resultados obtidos no presente trabalho indicam que o XR, nas doses utilizadas, não apresentou toxicidade aos organismos estudados.

De maneira geral, a atividade enzimática do solo não foi afetada pela adição do XR. Em condições de laboratório, as principais alterações foram observadas com as enzimas fosfatase ácida e arilsulfatase (Tabela 3). Observa-se que, aos 30 dias, a aplicação do XR causou redução na atividade dessas enzimas. Em condições de campo, o XR afetou apenas a atividade das enzimas urease e DHA. O efeito do 
XR sobre a atividade da enzima urease foi observado somente no primeiro cultivo, em que foi ajustado o modelo quadrático (Tabela 4). Em relação à atividade da DHA, a aplicação das doses de $750 \mathrm{~kg} \mathrm{ha}^{-1} \mathrm{e}$ $3.000 \mathrm{~kg} \mathrm{ha}^{-1}$ de XR provocaram redução na atividade dessa enzima, somente na avaliação realizada aos sete dias, do segundo cultivo de feijão. Os valores obtidos para a atividade das enzimas avaliadas estão dentro de uma ampla faixa de valores, obtidos em trabalhos com diferentes formas de uso do solo e em distintas condições edafoclimáticas (García-Gil et al., 2000; Marcote et al., 2001; Trannin et al., 2007; Lagomarsino et al., 2009).

As alterações verificadas na atividade das enzimas fosfatase e arilsulfatase em condições de laboratório, possivelmente, estão relacionados ao aporte de $\mathrm{P}$ e S realizados ao solo com o $\mathrm{XR}$, o que indica que esse subproduto pode aumentar a disponibilidade desses

Tabela 3. Atividade enzimática em solo incubado com doses crescentes de xisto retortado $(\mathrm{XR})^{(1)}$.

\begin{tabular}{|c|c|c|c|c|c|c|}
\hline Tratamento $^{(2)}$ & $\beta$ glicosidase $^{(3)}$ & Desidrogenase $^{(4)}$ & Diacetato de fluoresceína $^{(5)}$ & Fosfatase ácida $^{(3)}$ & Arilsulfatase $^{(3)}$ & Urease $^{(6)}$ \\
\hline & \multicolumn{6}{|c|}{$15 \operatorname{dias}^{(7)}$} \\
\hline XR0 & $44 a$ & $44 \mathrm{a}$ & $74 a$ & $303 b$ & $29 \mathrm{c}$ & $95 \mathrm{ab}$ \\
\hline XR750 & $40 \mathrm{a}$ & $41 \mathrm{a}$ & $77 \mathrm{a}$ & $351 \mathrm{a}$ & $31 \mathrm{c}$ & $55 \mathrm{bc}$ \\
\hline XR1500 & $42 \mathrm{a}$ & $44 a$ & $78 \mathrm{a}$ & $323 a b$ & $33 \mathrm{bc}$ & $113 \mathrm{a}$ \\
\hline \multirow[t]{2}{*}{ XR3000 } & $39 \mathrm{a}$ & $40 \mathrm{a}$ & $76 \mathrm{a}$ & $346 \mathrm{a}$ & $61 \mathrm{a}$ & $53 \mathrm{c}$ \\
\hline & \multicolumn{6}{|c|}{30 dias } \\
\hline XR0 & $16 \mathrm{a}$ & $21 \mathrm{a}$ & $65 \mathrm{a}$ & $906 \mathrm{a}$ & $18 \mathrm{a}$ & $95 \mathrm{ab}$ \\
\hline XR750 & $17 \mathrm{a}$ & $17 \mathrm{a}$ & $68 \mathrm{a}$ & $784 \mathrm{bc}$ & $15 b$ & $55 \mathrm{bc}$ \\
\hline XR1500 & $18 \mathrm{a}$ & $15 \mathrm{a}$ & $65 \mathrm{a}$ & $807 \mathrm{~b}$ & $15 b$ & $113 \mathrm{a}$ \\
\hline \multirow[t]{2}{*}{ XR3000 } & $19 \mathrm{a}$ & $21 \mathrm{a}$ & $62 \mathrm{a}$ & $751 \mathrm{~b}$ & $15 b$ & $53 \mathrm{c}$ \\
\hline & \multicolumn{6}{|c|}{$60 \operatorname{dias}^{(8)}$} \\
\hline XR0 & $43 b$ & $27 \mathrm{a}$ & $66 \mathrm{a}$ & $247 \mathrm{a}$ & $9 \mathrm{a}$ & $28 \mathrm{a}$ \\
\hline XR750 & $67 a$ & $35 \mathrm{a}$ & $53 \mathrm{c}$ & $201 b$ & $8 \mathrm{a}$ & $26 \mathrm{a}$ \\
\hline XR1500 & $64 \mathrm{a}$ & $41 \mathrm{a}$ & $64 a b$ & $214 \mathrm{ab}$ & $9 a$ & $39 a$ \\
\hline XR3000 & $41 \mathrm{~b}$ & $36 a$ & $62 b$ & $241 \mathrm{a}$ & $7 b$ & $19 \mathrm{a}$ \\
\hline
\end{tabular}

${ }^{(1)}$ Médias seguidas de letras iguais, nas colunas, não diferem entre si, pelo teste Tukey, a $5 \%$ de probabilidade. ${ }^{(2)}$ XR0, controle; XR750, solo + $750 \mathrm{~kg} \mathrm{ha}^{-1}$ de XR; XR1500, solo $+1.500 \mathrm{~kg} \mathrm{ha}^{-1} \mathrm{de}$ XR; XR3000, solo $+3.000 \mathrm{~kg} \mathrm{ha}^{-1} \mathrm{de} \mathrm{XR}^{\left({ }^{(3)}\right.} \mu \mathrm{g}$ de paranitrofenol g-1 de solo por hora. ${ }^{(4)} \mu \mathrm{g}$ de trifenil formazan $\mathrm{g}^{-1}$ de solo por hora. ${ }^{(5)} \mu \mathrm{g}$ de fluoresceína $\mathrm{g}^{-1}$ de solo por hora. ${ }^{(6)} \mathrm{mg} \mathrm{de} \mathrm{N} \mathrm{NH}_{4}{ }^{+} \mathrm{kg}^{-1}$ de solo por hora. ${ }^{(7)}$ Equação de regressão para arilsulfatase: $y=29,6+0,004 x-0,00005 x^{2}, R^{2}=0,99 * *$. ${ }^{(8)}$ Equação de regressão para $\beta$ glicosidase: $y=44,5+0,032 x-0,00001 x^{2}, R=0,79 * *$ **Significativo a $1 \%$ de probabilidade pelo teste $\mathrm{F}$.

Tabela 4. Atividade enzimática do solo e carbono da biomassa microbiana (CBM, $\left.\mathrm{mg} \mathrm{kg}^{-1}\right)$, em amostras de solo da camada de $0-5 \mathrm{~cm}$, coletadas após uma semana da aplicação do xisto retortado (A1) e ao florescimento (A2) do feijão(1).

\begin{tabular}{|c|c|c|c|c|c|c|c|c|c|c|c|c|c|c|}
\hline \multirow[t]{2}{*}{ Tratamento $^{(2)}$} & \multicolumn{2}{|c|}{ Urease $^{(3)}$} & \multicolumn{2}{|c|}{ Arilsulfatase $^{(4)}$} & \multicolumn{2}{|c|}{$\beta$ glicosidase $^{(4)}$} & \multicolumn{2}{|c|}{ Diacetato de fluoresceína $^{(5)}$} & \multicolumn{2}{|c|}{ Desidrogenase $^{(6)}$} & \multicolumn{2}{|c|}{ Fosfatase ácida $^{(4)}$} & \multicolumn{2}{|c|}{ CBM } \\
\hline & $\mathrm{A} 1^{(7)}$ & $\mathrm{A} 2^{(8)}$ & $\mathrm{A} 1$ & $\mathrm{~A} 2$ & $\mathrm{~A} 1$ & $\mathrm{~A} 2$ & A1 & $\mathrm{A} 2$ & $\mathrm{~A} 1$ & $\mathrm{~A} 2$ & $\mathrm{~A} 1$ & A2 & $\mathrm{A} 1^{(9)}$ & $\mathrm{A} 2$ \\
\hline & \multicolumn{14}{|c|}{ Primeiro cultivo } \\
\hline $\mathrm{NPK}+\mathrm{XR} 0$ & $9 \mathrm{c}$ & $16 \mathrm{c}$ & $27 \mathrm{a}$ & $24 \mathrm{a}$ & $45 \mathrm{a}$ & $32 \mathrm{a}$ & $41 \mathrm{a}$ & $59 \mathrm{a}$ & $47 \mathrm{a}$ & $36 \mathrm{a}$ & $129 \mathrm{a}$ & $134 \mathrm{a}$ & $104 a$ & $153 \mathrm{a}$ \\
\hline $\mathrm{NPK}+\mathrm{XR750}$ & $13 b$ & $24 b$ & $32 \mathrm{a}$ & $28 \mathrm{a}$ & $46 \mathrm{a}$ & $29 a$ & $35 \mathrm{a}$ & $62 \mathrm{a}$ & $41 \mathrm{a}$ & $38 \mathrm{a}$ & $139 a$ & $145 \mathrm{a}$ & $117 \mathrm{a}$ & $186 \mathrm{a}$ \\
\hline $\mathrm{NPK}+\mathrm{XR} 1500$ & $24 \mathrm{a}$ & $44 \mathrm{a}$ & $26 \mathrm{a}$ & $26 \mathrm{a}$ & $45 \mathrm{a}$ & $26 \mathrm{a}$ & $41 \mathrm{a}$ & $59 \mathrm{a}$ & $41 \mathrm{a}$ & $32 \mathrm{a}$ & $127 \mathrm{a}$ & $132 \mathrm{a}$ & $129 \mathrm{a}$ & $170 \mathrm{a}$ \\
\hline $\mathrm{NPK}+\mathrm{XR} 3000$ & $25 \mathrm{a}$ & $46 \mathrm{a}$ & $24 \mathrm{a}$ & $28 \mathrm{a}$ & $41 \mathrm{a}$ & $29 \mathrm{a}$ & $47 \mathrm{a}$ & $61 \mathrm{a}$ & $26 \mathrm{a}$ & $42 \mathrm{a}$ & $130 \mathrm{a}$ & $153 \mathrm{a}$ & $131 \mathrm{a}$ & $186 a$ \\
\hline \multirow[t]{2}{*}{ CV (\%) } & 9 & 8 & 14 & 25 & 16 & 10 & 38 & 4 & 34 & 17 & 9 & 9 & 22 & 20 \\
\hline & \multicolumn{14}{|c|}{ Segundo cultivo } \\
\hline $\mathrm{NPK}+\mathrm{XR} 0$ & $40 \mathrm{a}$ & $63 a$ & $27 \mathrm{a}$ & $11 \mathrm{a}$ & $50 \mathrm{a}$ & $42 a$ & $55 \mathrm{a}$ & $24 \mathrm{a}$ & $101 \mathrm{a}$ & $46 a$ & $120 \mathrm{a}$ & $205 \mathrm{a}$ & $269 a$ & $81 \mathrm{a}$ \\
\hline $\mathrm{NPK}+\mathrm{XR750}$ & $44 a$ & $65 \mathrm{a}$ & $37 \mathrm{a}$ & $12 \mathrm{a}$ & $53 a$ & $48 \mathrm{a}$ & $57 \mathrm{a}$ & $23 a$ & $52 \mathrm{c}$ & $52 \mathrm{a}$ & $124 \mathrm{a}$ & $216 \mathrm{a}$ & $160 \mathrm{bc}$ & $78 \mathrm{a}$ \\
\hline $\mathrm{NPK}+\mathrm{XR} 1500$ & $50 \mathrm{a}$ & $59 a$ & $27 \mathrm{a}$ & $12 \mathrm{a}$ & $50 \mathrm{a}$ & $44 a$ & $56 \mathrm{a}$ & $23 a$ & $83 \mathrm{ab}$ & $49 a$ & $127 \mathrm{a}$ & $187 \mathrm{a}$ & $158 \mathrm{c}$ & $47 \mathrm{a}$ \\
\hline $\mathrm{NPK}+\mathrm{XR} 3000$ & $46 \mathrm{a}$ & $48 \mathrm{a}$ & $20 \mathrm{a}$ & $10 \mathrm{a}$ & $46 \mathrm{a}$ & $46 \mathrm{a}$ & $54 \mathrm{a}$ & $22 \mathrm{a}$ & $62 \mathrm{bc}$ & $44 \mathrm{a}$ & $110 \mathrm{a}$ & $208 \mathrm{a}$ & $121 \mathrm{c}$ & $39 \mathrm{a}$ \\
\hline CV (\%) & 28 & 31 & 29 & 16 & 12 & 17 & 11 & 9 & 12 & 24 & 19 & 8 & 13 & 33 \\
\hline
\end{tabular}

(1)Médias seguidas de letras iguais, nas colunas, não diferem entre si, pelo teste Tukey, a $5 \%$ de probabilidade. ${ }^{(2)} \mathrm{NPK}+\mathrm{XR} 0$, controle; NPK $+\mathrm{XR} 750, \mathrm{NPK}+750 \mathrm{~kg}$ $\mathrm{ha}^{-1} \mathrm{de} \mathrm{XR}$; NPK+XR1500, NPK + $1.500 \mathrm{~kg} \mathrm{ha}^{-1} \mathrm{de} \mathrm{XR}$; NPK+XR3000, NPK + $3.000 \mathrm{~kg} \mathrm{ha}^{-1}$ de XR. ${ }^{(3)} \mathrm{mg} \mathrm{de} \mathrm{N} \mathrm{NH}_{4}{ }^{+} \mathrm{kg}^{-1}$ de solo por hora. ${ }^{(4)} \mu \mathrm{g}$ de paranitrofenol $\mathrm{g}^{-1}$ de solo por hora. ${ }^{(5)} \mu \mathrm{g}$ de fluoresceína $\mathrm{g}^{-1}$ de solo por hora. ${ }^{\left({ }^{(}\right)} \mu \mathrm{g}$ de trifenil formazan $\mathrm{g}^{-1}$ de solo por 24 horas. ${ }^{(7)}$ Primeiro cultivo: $\mathrm{y}=8,3+0,01 \mathrm{x}-0,000002 \mathrm{x}^{2}$, $\mathrm{R}^{2}=0,92 * * .{ }^{(8)}$ Primeiro cultivo: $\mathrm{y}=14,0+0,02 \mathrm{x}-0,000004 \mathrm{x}^{2}, \mathrm{R}^{2}=0,92 * *$. ${ }^{(9)}$ Segundo cultivo: $\mathrm{y}=259,3+0,11 \mathrm{x}-0,00002 \mathrm{x}^{2}, \mathrm{R}^{2}=0,90 * *$. ** Significativo a $1 \%$ de probabilidade pelo teste $\mathrm{F}$. 
nutrientes no solo para as plantas e microrganismos. Trannin et al. (2007) verificaram que, após dois anos de aplicação de lodo de esgoto, acrescido de $\mathrm{P}_{2} \mathrm{O}_{5}$, houve diminuição na atividade da fosfatase ácida, em comparação ao solo controle. As demais enzimas avaliadas não tiveram sua atividade alterada pela aplicação do XR, condição que pode estar relacionada à baixa quantidade de $\mathrm{C}$ adicionada com o $\mathrm{XR}$ e ao seu elevado grau de recalcitrância. Os resultados obtidos com as enzimas, em condições de campo, após duas aplicações de XR, aliados aos resultados de CBM, do $\mathrm{qCO}_{2}$ e do teste ecotoxicológico, em condições de laboratório, indicam que o uso do XR não provoca a degradação biológica do solo. Ainda, a redução da emissão de $\mathrm{CO}_{2}$, pela aplicação do $\mathrm{XR}$, parece indicar que o uso do XR em solos agrícolas pode ser uma importante estratégia para preservar o $\mathrm{C}$ no solo, por reduzir a mineralização da MOS.

\section{Conclusões}

1. A aplicação do xisto retortado ao solo reduz a emissão de $\mathrm{CO}_{2}$, sem reduzir a biomassa microbiana do solo.

2. O xisto retortado, mesmo quando reaplicado em doses crescentes ao solo até o limite de $3.000 \mathrm{~kg} \mathrm{ha}^{-1}$, não causa impactos negativos sobre a atividade enzimática do solo.

\section{Agradecimentos}

À Petrobras, pelo auxílio financeiro, por meio da Unidade de Industrialização do Xisto, em São Mateus do Sul, PR.

\section{Referências}

AFONSO, J.C.; SCHMAL, M.; CARDOSO, J.N.; FRETY, R. Hydrotreatment of Irati shale oil: behavior of the aromatic fraction. Industrial and Engineering Chemistry Research, v.30, p.2133-2137, 1991.

ALEF, K. Estimation of the hydrolysis of fluorescein diacetate. In: ALEF, K.; NANNIPIERI, P. (Ed.). Methods in applied soil microbiology and biochemistry. New York: Academic, 1995. p.232-233.

ANDERSON, T.H.; DOMSCH, K.H. The metabolic quotient for $\mathrm{CO}_{2}\left(\mathrm{qCO}_{2}\right)$ as a specific activity parameter to assess the effects of environmental conditions, such as $\mathrm{pH}$, on the microbial biomass of forest soils. Soil Biology and Biochemistry, v.25, p.393-395, 1993.
ANJOS, A.R.M. dos; REISSMANN, C.B. Influência dos resíduos da mineração do xisto no crescimento e no teor foliar de $\mathrm{Cd}$, Co e Cr em plantas de aveia-preta. Ciência Rural, v.26, p.75-79, 1996.

BRASIL. Ministério da Agricultura, Pecuária e Abastecimento. Secretaria de Defesa Agropecuária. Portaria n ${ }^{\circ} 402$, de 22 de julho de 2010. Diário Oficial [da] República Federativa do Brasil, 23 jul. 2010. Seção 1, p.3.

BRASIL. Ministério do Meio Ambiente. Conselho Nacional do Meio Ambiente. Resolução no 375, de 29 de agosto de 2006. Define critérios e procedimentos, para o uso agrícola de lodos de esgoto gerados em estações de tratamento de esgoto sanitário e seus produtos derivados, e dá outras providências. Diário Oficial [da] República Federativa do Brasil, 30 ago. 2006. Seção 1, p.141-146.

BROOKES, P.C. The use of microbial parameters in monitoring soil pollution by heavy metals. Biology and Fertility Soils, v.19, p.269-279, 1995.

CESSA, R.M.A.; CELI, L.; VITORINO, A.C.T.; NOVELINO, J.O.; BARBERIS, E. Área superficial específica, porosidade da fração argila e adsorção de fósforo em dois Latossolos Vermelhos. Revista Brasileira Ciência do Solo, v.33, p.1153-1162, 2009.

COGO, S.L. Um estudo dos subprodutos e rejeitos do xisto por ressonância paramagnética eletrônica. 2008. 94p. Dissertação (Mestrado) - Universidade Estadual de Ponta Grossa, Ponta Grossa.

GARCÍA-GIL, J.C.; PLAZA, C.; SOLER-ROVIRA, P.; POLO, A. Long-term effects of municipal solid waste compost application on soil enzyme activities and microbial biomass. Soil Biology and Biochemistry, v.32, p.1907-1913, 2000.

INTERNATIONAL ORGANIZATION FOR STANDARDIZATION. ISO/FDIS 17512-1: avoidance test for testing the quality of soils and the toxicity of chemicals on behaviour: part 1: test with earthworms (Eisenia fetida and Eisena andrei). Geneva: ISO, 2002.

KUZYAKOV, Y. Priming effects: interactions between living and dead organic matter. Soil Biology and Biochemistry, v.42, p.1363-1371, 2010.

KUZYAKOV, Y.; FRIEDEL, J.K.; STAHR, K. Review of mechanisms and quantification of priming effects. Soil Biology and Biochemistry, v.32, p.1485-1498, 2000.

LAGOMARSINO, A.; MOSCATELLI, M.C.; DI TIZIO, A.; MANCINELLI, S.; GREGO, S.; MARINARI, S. Soil biochemical indicators as a tool to assess the short-term impact of agricultural management on changes in organic $\mathrm{C}$ in a Mediterranean environment. Ecological Indicators, v.9, p.518-527, 2009.

LAMBAIS, M.R.; CARMO, J.B. do. Impactos da aplicação de biossólidos na microbiota de solos tropicais. Revista Brasileira de Ciência do Solo, v.32, p.1129-1138, 2008.

MACHADO, A.A.; CONCEIÇÃO, A.R. Winstat: sistema de análise estatística para Windows. Versão 2.0. Pelotas: UFPel, 2003.

MARCOTE, I.; HERNANDEZ, T.; GARCIA, C.; POLO, A. Influence of one or two successive annual applications of organic fertilisers on the enzyme activity of a soil under barley cultivation. Bioresource Technology, v.79, p.147-154, 2001. 
MIOTTO, D.M.M.; MACHADO, N.R.C.F. Utilização de xisto retortado como matéria-prima em síntese de zeólitas. Acta Scientiarum. Technology, v.28, p.39-45, 2006.

PEREIRA, H.S.; VITTI, G.C. Efeito do uso do xisto em características químicas do solo e nutrição do tomateiro. Horticultura Brasileira, v.22, p.317-322, 2004.

PIMENTEL, P.M.; SILVAJUNIOR, C.N.; MELO, D.M.A.; MELO, M.A.F.; MALDONADO, G.; HENRIQUE, D.M. Caracterização e uso de xisto para adsorção de chumbo (II) em solução. Cerâmica, v.52, p.194-199, 2006

SANTOS, H.G. dos; JACOMINE, P.K.T.; ANJOS, L.H.C. dos; OLIVEIRA, V.A. de; OLIVEIRA, J.B. de; COELHO, M.R.; LUMBRERAS, J.F.; CUNHA, T.J.F. (Ed.). Sistema brasileiro de classificação de solos. 2.ed. Rio de Janeiro: Embrapa Solos, 2006. 306p.

SÃO PAULO (Estado). Companhia de Tecnologia de Saneamento Ambiental. Decisão de diretoria n ${ }^{\circ} 195-2005$ - E, de 23 de novembro de 2005. Dispõe sobre a aprovação dos valores orientadores para solos e águas subterrâneas no Estado de São Paulo - 2005, em substituição aos valores orientadores de 2001, e dá outras providências. Disponível em: <http://www.cetesb.sp.gov.br/solo/ relatorios/tabela_valores_2005.pdf $>$. Acesso em: 25 fev. 2011.

SISINNO, C.L.S.; BULUS, M.R.M.; RIZZO, A.C.; MOREIRA, J.C. Ensaio de comportamento com minhocas (Eisenia fetida) para avaliação de áreas contaminadas: resultados preliminares para contaminação por hidrocarbonetos. Journal of the Brazilian Society of Ecotoxicology, v.1, p.137-140, 2006.

SOUZA, C.A. de; REIS JUNIOR, F.B. dos; MENDES, I. de C.; LEMAINSKI, J.; SILVA, J.E. da. Lodo de esgoto em atributos biológicos do solo e na nodulação e produção de soja. Pesquisa Agropecuária Brasileira, v.44, p.1319-1327, 2009.

SPARLING, G.P.; WEST, A.W. A direct extraction method to estimate soil microbial C: calibration in situ using microbial respiration and ${ }^{14} \mathrm{C}$ labelled cells. Soil Biology and Biochemistry, v.20, p.337-343, 1988.

STARK, J.M.; REDENTE, E.F. Plant uptake and cycling of trace elements on retorted oil shale disposal piles. Journal of Environmental Quality, v.19, p.495-501, 1990.
STOTZKY, G. Microbial respiration. In: BLACK, C.A. (Org.). Methods of soil analysis: chemical and microbiological properties. Madison: American Society of Agronomy, 1965. v.2, p.1550-1572.

SYLVIA, D.M.; FUHRMANN, J.J.; HARTEL, P.G.; ZUBERER, D.A. Principles and applications of soil microbiology. New Jersey: Prentice Hall, 1998. 550p.

TABATABAI, M. Soil enzymes. In: WEAVER, R.W.; ANGLE, S.; BOTTOMLEY, P.; BEZDICEK, D.; SMITH, S.; TABATABAI, A.; WOLLUM, A. (Ed.). Methods of soil analysis: microbiological and biochemical properties. Madison: Soil Science Society of America, 1994. pt.2, p.778-835. (Soil Science Society of America. Book series, 5).

THALMANN, A. Zur Methodik der Bestimmung der Dehydrogenaseaktivität im Boden mittels Triphenyltetrazoliumchlorid (TTC). Landwirtschaftliche Forschung, v.21, p.249-258, 1968.

TRANNIN, I.C. de B.; SIQUEIRA, J.O.; MOREIRA, F.M. de S. Características biológicas do solo indicadoras de qualidade após dois anos de aplicação de biossólido industrial e cultivo de milho.

Revista Brasileira de Ciência do Solo, v.31, p.1173-1184, 2007.

UNITED STATES ENVIRONMENTAL PROTECTION AGENCY. Method 8270C: semivolatile organic compounds by gas chromatography/mass spectrometry (GC/MS). 1996. 54p. Revision 3. Available at: <http://accustandard.com/asi/pdfs/epa methods/8270c.pdf>. Accessed on: 9 Oct. 2011.

VANCE, E.D.; BROOKES, P.C.; JENKINSON, D.S. An extraction method for measuring soil microbial biomass-C. Soil Biology and Biochemistry, v.19, p.703-707, 1987.

WISEMAN, C.L.S.; PÜTTMANN, W. Interactions between mineral phases in the preservation of soil organic matter. Geoderma, v.134, p.109-118, 2006.

ZIMMERMAN, A.R.; GAO, B.; AHN, M.-Y. Positive and negative carbon mineralization priming effects among a variety of biochar-amended soils. Soil Biology and Biochemistry, v.43, p.1169-1179, 2011.

Recebido em 11 de março de 2011 e aprovado em 5 de outubro de 2011 